\title{
Alfabetizando e letrando... o despertar e a tessitura de conhecimentos nos caminhos trilhados
}

\author{
Alphabetization and literacy... the waking \\ and knowledge's weft in the trailed ways
}

Andrea da Paixão FERNANDES

\begin{abstract}
RESUMO
O mundo está impregnado das mais variadas formas de linguagem, mas a linguagem oral e a escrita, meios privilegiados que usamos para nos comunicarmos, representam uma diferenciação importante em relação aos outros seres vivos. Só os seres humanos se comunicam por meio delas. Apesar das grandes diferenças sócio-culturais em sua utilização, os indivíduos delas se apropriam para interagir com o mundo e seus semelhantes. No entanto, para que a prática da leitura faça sentido, vamos lendo o mundo, como nos ensinou o mestre Paulo Freire. Aprendendo a ler, lendo. Aprendendo a escrever, escrevendo. Compreendendo e se apropriando do que é lido. Este trabalho retrata a experiência do aprender a ler e escrever com sentido para si e para o coletivo e permite uma reflexão sobre a construção e a apropriação do ensinar e aprender tendo em vista os saberes escolares (e não escolares) que se constituem nas/pelas experiências de alfabetização e letramento a partir de diferentes estratégias de leitura com crianças, jovens e adultos.
\end{abstract}

Palavras-chave: alfabetização, escrita, leitura, letramento.

\begin{abstract}
The world is full of several different types of languages, but oral and written languages are a privilege we have, as human beings, to communicate. We make use of them to interact with the world and our fellows, in spite of the sociocultural differences among us. However, we read the world to make reading meaningful, as the great Brazilian educator Paulo Freire taught us. We learn reading by reading, the same way we learn writing by writing. We understand language by building meaning from what we read. This work shows the experience of learning to read and to write from meaning to ourselves and to the world, and it allows some reflections about teaching and learning taking into consideration previous knowledge, which is part literacy from different reading strategies with children, teenagers and adults.
\end{abstract}

Index Terms: alphabetization, literacy, reading, writing. 


\title{
Introdução
}

\section{Iniciando o diálogo...}

\author{
Um galo sozinho não tece uma manhã: \\ ele precisará sempre de outros galos. \\ De um que apanhe esse grito que ele \\ e o lance a outro; de um outro galo \\ que apanhe o grito de um galo antes e o lance... \\ (João Cabral de Melo Neto)
}

O mundo está impregnado das mais variadas formas de linguagem, mas a linguagem oral e a escrita, meios privilegiados que usamos em nossa comunicação, representam uma diferenciação importante em relação aos outros seres vivos. Só os seres humanos se comunicam por meio delas. Apesar das grandes diferenças socioculturais em sua utilização, os indivíduos delas se apropriam para interagir com o mundo e com seus semelhantes.

Aprende-se a ler, lendo e é lendo que nos tornamos leitores. Aprender a ler e a escrever requer que uma complexa rede seja tecida. Essa tessitura se constrói a partir dos contatos diários, das histórias contadas, das informações trocadas e enriquecidas pelo saber que já adquirimos e, também, pelo saber do outro.

Assim — para que a prática da leitura faça sentido — vamos lendo o mundo, como nos ensinou o mestre Paulo Freire. Aprendendo a ler, lendo. Aprendendo a escrever, escrevendo. Compreendendo e se apropriando do que é lido. Para isso, é preciso que sejamos capazes de fazer, primeiramente, uma leitura contextualizada do mundo, com tudo o que nos cerca. Ou seja, é preciso que, antes de estarmos alfabetizados na língua materna, estejamos alfabetizados politicamente, pois, assim, teremos melhores condições de nos apropriarmos do sentido e do conceito de/sobre o que lemos. Cabe ressaltar que Freire já considerava a perspectiva do letramento na aprendizagem da leitura e da escrita, embora não fizesse uso deste termo. 
Esse é o nosso lócus de referência para a apresentação das interações e conexões que permitem trilhar caminhos que constituem desafios para que o encontro com o prazer de ler (e de escrever) se efetive.

\section{Interações e Conexões: desafios do encontro com o prazer de ler}

Este século requer a necessidade de interagirmos, de forma cada vez mais ágil, com as diferentes linguagens que perpassam o cotidiano da nossa sociedade. Apresenta, também, a necessidade de essa mesma sociedade ousar propor ações que permitam, cada vez mais, a formação de leitores críticos e sabedores das possibilidades de sua atuação.

Refletindo sobre as práticas de alfabetização com crianças e, também, com jovens e adultos, relatadas na pesquisa-ação da prática docente e de seus vieses feitos cotidianamente, percebemos como essas práticas permitem repensar as teorias e como, por sua vez, a partir dessas teorias, podem ser reformuladas, ampliadas ou aperfeiçoadas.

A leitura e produção da escrita só são efetivamente tecidas, entretanto, a partir do momento em que há o encontro dialógico do sujeito com o texto lido e, também, com o sentido do que possa ser escrito.

Considerando o prazer necessário para que esse encontro aconteça e torne possível tais produções, eu me recordo do livro de Marina Colasanti Fragatas para terras distantes - que, certamente, representou para mim uma leitura muito prazerosa. Nele, sua autora narra uma experiência que demonstra como é importante a leitura contextualizada. Relatando o encontro de suas filhas com o gosto pela leitura, confessa que tentou transferir, com as duas, a sua experiência de se descobrir como leitora, ainda na infância. Com uma deu certo, entretanto, com a outra...

Minha filha - ocupemo-nos aqui da que não nasceu leitora - foi criada em Ipanema. Numa cidade que parecia um eterno playground. $\mathrm{Na}$ era da televisão. Cheia de amigos, praias, programas. Em um colégio animado, inteligente, com 
fonte de prazer, mas como algo que tomaria o tempo de um prazer mais imediato, ou pelo menos mais evidente.

[...] podemos até especular se o fato de ser na família a única que não lia não era usado por ela como uma forma distintiva.

É evidente, porém, que o pouco que havia lido na infância não havia conseguido lhe transmitir a sensação de que os livros contêm coisas importantes e prazerosas.

Até hoje tento entender por quê.

Tinha à sua disposição, desde o início, vasta escolha. Entre o que lhe era oferecido estava, sem sombra de dúvida, o melhor. Podia pegar um livro, começar e, se não achasse interessante, trocá-lo na mesma hora por outro e por outro ainda, até achar o que lhe agradasse, sem qualquer tipo de problema - como observações da nossa parte ou até mesmo restrições econômicas. Não estava, nessa caçada, limitada à temível faixa etária. Pois dispunha de livros para todas as idades, uma vez que a irmã leitora é seis anos mais velha. Nem estava presa às escolhas da irmã, já que, como autores e jornalistas, meu marido e eu constantemente recebíamos livros das editoras.

O fato inegável é que, apesar disso tudo, nenhum livro aderiu nela. Até Christiane F. (COLASANTI, 2004, p. 30-31).

A história que Marina Colasanti conta permite perceber que o gosto pela leitura só aflora quando identificamo-nos, de alguma forma, com o texto que está sendo lido. Por que começo a falar sobre a formação do leitor para abordar os desafios da alfabetização e do letramento? E o que é alfabetização? O que é letramento? O que os diferencia, mas também os une?

Iniciemos, pois, nossa reflexão pela definição de alfabetização. Leda Tfouni define alfabetização como o processo de "aquisição da escrita enquanto aprendizagem de habilidades para leitura, escrita e as chamadas práticas de linguagem" (TFOUNI, 1997, p. 9). Alfabetizar é, portanto, tornar o sujeito um ser capaz de ler e escrever, ou seja, reconhecer o alfabeto e as possibilidades de organização de palavras, frases, textos. Nesta concepção, o sujeito é capaz de decodificar os símbolos (letras) e reconhecêlas numa organização estrutural, que é a língua escrita. Então, se o sujeito consegue ler e escrever pode-se dizer que ele está alfabetizado. 
Letramento, por sua vez, é uma expressão que chega ao Brasil bem recentemente, na segunda metade da década de 1980, sendo a versão em Língua Portuguesa da expressão inglesa literacy. Segundo Magda Soares,

[...] etimologicamente, a palavra literacy vem do latim littera (letra), com o sufixo $-c y$, que denota qualidade, condição, estado, fato de ser. [...] Ou seja: literacy é o estado ou condição que assume aquele que aprende a ler e escrever." (SOARES, 2003, p. 17).

Tfouni (1997) ao conceituar escrita, alfabetização e letramento considera que a alfabetização se restringe à aquisição das habilidades de escrita e de leitura. No entanto, ao analisar o conceito de letramento considera que:

[...] focaliza os aspectos sócio-históricos da aquisição da leitura. (...) procura ainda saber quais práticas psiciossociais substituem as práticas "letradas" em sociedades ágrafas. Desse modo [segundo a autora], o letramento tem por objetivo investigar não somente quem é alfabetizado, mas também quem não é alfabetizado, e, nesse sentido desliga-se de verificar o individual e centraliza-se no social (TFOUNI, 1997, p. 10).

Referenciada nos estudos de Leda Tfouni, Mary Kato e Angela Kleiman, Soares (2003) apresenta duas dimensões da perspectiva do letramento: a individual e a coletiva. A dimensão individual considera a leitura e a escrita como suportes tecnológicos sendo contemplada, a primeira, por "um conjunto de habilidades lingüísticas e psicológicas, que se estendem desde a habilidade de decodificar palavras escritas até a capacidade de compreender textos escritos" (SOARES, 2003, p. 68). Já as habilidades lingüísticas e psicológicas exigidas pela escrita se diferenciam, e "estendem-se da habilidade de registrar unidades de som até a capacidade de transmitir significado de forma adequada a um leitor potencial" (SOARES, 2003, p. 69). Ambas são, portanto, categorias complementares. A dimensão social define que "letramento é o que as pessoas fazem com as habilidades de leitura e de escrita em um contexto específico, e como essas habilidades 
se relacionam com as necessidades, valores e práticas sociais" (SOARES, 2003, p. 72).

Diante do exposto, pode-se afirmar que alfabetizar no contexto do letramento pressupõe o desenvolvimento das habilidades de leitura e de escrita por meio da aprendizagem individual e das interações que se desabrocham no/pelo coletivo, ou seja, a partir das práticas sociais produzidas e desenvolvidas num determinado contexto social.

De acordo com essa perspectiva, o sujeito — criança ou adulto está alfabetizado na perspectiva do letramento quando, além de ler e escrever, faz uso social dessa leitura e escrita e interage com as diferentes possibilidades que se apresentam. Isso ocorre a partir do envolvimento desses sujeitos com as práticas sociais e com o uso cotidiano de leitura e escrita, visto que já se apropriaram das tecnologias necessárias para ler e escrever.

Ser alfabetizado em nossa sociedade e apropriar-se de suas possibilidades de uso garante a todo indivíduo a condição e a autoridade de ser um cidadão com direitos ampliados e garantidos. Além disso, essas possibilidades que se apresentam a partir da aquisição e da apropriação da leitura e da escrita, ou melhor, a partir da aquisição do estado de alfabetizado, na perspectiva do letramento, potencializam não só a sua condição de cidadão que vive e que, portanto, precisa se articular numa sociedade letrada, como também, no caso dos alunos jovens e adultos, a garantia de acesso ou continuidade no mundo do trabalho.

Porém, para abordar o prazer da leitura e da escrita em espaçostempos escolares, é preciso considerar a importância da escola como um dos espaços de formação do leitor. Cumpre lembrar que, para grande parcela da nossa sociedade, muitas vezes, ela representa o único desses espaços.

Para desenvolver a aquisição e a apropriação da escrita pelos estudantes é fundamental que a escola tenha um compromisso verdadeiro com a valorização da realidade desses estudantes e de suas vivências. Nas 
práticas pedagógicas que se destinam a trabalhar os processos de aquisição e de apropriação da leitura e da escrita com real significado para esses sujeitos, é de extrema importância que a escola valorize a troca entre a realidade do aluno e os saberes escolares (chamo de saberes escolares tudo o que a escola apresenta para a sociedade como conteúdos a serem ensinados pelo e no espaço-tempo escolar).

A escola - e quando falo "escola", estou me referindo às práticas pedagógicas que ali se realizam e que, por sua vez, possibilitam que a escola seja mais (ou menos) agradável para os estudantes — deve valorizar, cada vez mais, os saberes na organização do seu currículo, do seu projeto político-pedagógico e mesmo do seu planejamento cotidiano, os saberes e, portanto, os currículos individuais que estão expressos e se manifestam em cada situação de aprendizagem que acompanha professores e estudantes nos seus afazeres e descobertas cotidianas, de forma a impregnar o fazer educativo de sentido e de significado.

E, assim, voltamos ao nosso ponto de partida.

Marina Colasanti contou um pouco de sua experiência e, certamente, de sua angústia de mãe-escritora para despertar o gosto pela leitura em sua filha mais nova, de modo a "(trans)formá-la" em leitora. Várias foram as tentativas de Marina. Mas o gosto pela leitura só surgiu em sua filha, quando a mesma se deparou com um livro que, verdadeiramente, dialogasse com ela. Por que estou dizendo isso? Porque ler não tem sentido e não causa prazer, se não tocar a emoção do leitor de alguma maneira. Ler é gostoso somente quando interagimos com o que estamos lendo; quando o lido tem significado para nós. Quando isso acontece, nos agarramos ao livro ou ao texto e não queremos parar até chegar ao seu ponto final. Essa emoção, a busca desse prazer é fundamental para que tanto crianças, como jovens e adultos queiram ler e, antes disso, queiram aprender a ler e a escrever.

Nesse sentido, façamos uma breve análise acerca das "leituras escolares". Intitulamos "leituras escolares" aquelas apresentadas pelas 
cartilhas ou às que, por ventura, são produzidas nos espaços escolares. Ainda que permitam que crianças, jovens e adultos adquiram o código escrito tornando-as, portanto, capazes de ler e escrever, nem sempre essa alfabetização vem acompanhada de uma verdadeira apropriação da leitura e da escrita e, além disso, do verdadeiro prazer em ler e escrever. Ou seja, nem sempre estamos formando leitores e escritores competentes quando utilizamos determinadas leituras ditas escolares. Um dos aspectos que embasam o hiato que aqui se apresenta é, certamente, o fato de não haver, nas diferentes sociedades letradas, uma leitura que seja escolar e outra que seja do mundo, haja vista que todas as formas, possibilidades e estratégias de leitura devem perpassar os diversos espaços-tempos, considerando os aspectos sociais, políticos e culturais, dentre outros.

Estudos apresentados por Kleiman (2004) ressaltam que o modelo ideológico de letramento possibilita determinar o enfoque a ser abordado nos e pelos processos de formação do leitor e do escritor a partir das práticas alfabetizadoras. Tal aspecto torna-se viável porque tal modelo considera tanto os aspectos socioculturais, como os que determinam as estruturas de poder nas sociedades. Nesse sentido, é correto afirmar que as práticas de letramento são determinadas nos contextos sociais e culturais e, assim, os significados que a leitura e a escrita assumem nos diferentes grupos sociais são contextualizados e historicamente determinados.

Um dos maiores desafios que se apresentam atualmente para professoras e professores alfabetizadores é o trabalho de formação de leitores e escritores. Para refletirmos sobre algumas possibilidades para se enfrentar esse desafio, quero contar duas outras histórias. Não a de Marina Colasanti, mas a minha, de criança que, de certa forma, tem alguma semelhança com a da filha mais nova da Marina e, também, a minha experiência de professora alfabetizadora.

A primeira dessas histórias é de como me percebi passando de nãoleitora a leitora. Lembro-me da minha infância num conceituado colégio da 
zona oeste do Rio de Janeiro. Uma escola tradicional na década de 19701980, da qual tenho muitas saudades, mas também o registro de como aprender a não gostar de ler. Estava na $3^{\mathrm{a}}$ série quando a professora comunicou à turma que precisávamos ler o livro Uma noite no Jardim Zoológico (acho que até hoje sou capaz de contar essa história). Li e reli esse livro por várias tardes, à sombra da mangueira do quintal da minha casa ou deitada na cama de meus pais, mas, apesar desse cenário sedutor, algo muito me incomodava. Lia e relia, porque sabia que faria uma prova sobre aquele livro. Esse foi o primeiro de muitos... de muitos desgostos pela leitura, pois além de experimentar o sentido da obrigatoriedade, ninguém me perguntava se eu queria ou não ler aquele livro. $\mathrm{Na} 4^{\mathrm{a}}$ série, foram mais livros. As histórias eram fantásticas, mas o fato de ser obrigatório, de ter um tempo que, na essência, era o tempo da escola, para finalizar a leitura me incomodava e me levava a não querer ler. Por que eu tinha de ler A mina de ouro $^{1}$ no primeiro bimestre? Por que não podia começar por $O$ cachorrinho Samba? E por que No rastro de Azulão, Cisco e Mangarito ${ }^{2}$ - um dos livros cuja leitura realmente me deu prazer - ficou para o final do ano?

Depois disso e para começar a encurtar essa contação, a escola indicou a leitura de Capitães de areia $^{3}$. Comecei entusiasmada, pois sempre via meus pais lendo Jorge Amado da coleção de capa dura que, até hoje, tenho na estante. Pena que foi só o começo... Aos dez anos, não gostei da história. Não gostei, porque não entendi. Ainda era cedo para eu dialogar e interagir com os escritos de Jorge Amado, mas a escola não se permitiu perceber isso. Nesse mesmo ano, li e reli com prazer $O$ menino do dedo verde ${ }^{4}$, de tal modo que, de vez em quando, ainda hoje, releio as adoráveis aventuras de Tistu. Quanto a Capitães de areia, outra escola me fez voltar a ele quando estava na $8^{\mathrm{a}}$ série. Dessa vez, ao contrário da experiência

\footnotetext{
${ }^{1}$ DUPRÉ, Maria José. (19--). A mina de ouro. São Paulo: Ática.

${ }^{2}$ PRADO, Lucília Junqueira de Almeida. (1982). No rastro de Azulão, Cisco e Mangarito. Rio de Janeiro: Record.

${ }^{3}$ AMADO, Jorge. (1968). Capitães de areia. São Paulo: Martins Editora.

${ }^{4}$ DRUON, Maurice. (1982). O menino do dedo verde. Rio de Janeiro: José Olympio.
} 
anterior, foi interessante. Lembro-me que fomos, inclusive, assistir à peça teatral sobre o romance de Amado, no Teatro Ipanema. Adorei! Nessa época, eu já estava com os meus treze anos.

Cheguei ao curso de Pedagogia na Universidade do Estado do Rio de Janeiro (UERJ) sem gostar verdadeiramente de ler. Quando vi quantos textos teria de ler e estudar, concluí que estava diante de duas opções que delineariam a escolha de um caminho a trilhar: ou eu descobria o meu interesse e gosto pela leitura, ou precisaria mudar de curso; mas todos os textos eram muito interessantes pra mim, eu queria ler e reler todos. Parecia que, finalmente, algo mágico acontecia na minha relação com a leitura. Era prazeroso ler os livros da área de Educação e os textos indicados pelos professores. Descobri, na graduação, o prazer de ler! Desde então, tenho vivenciado muitas experiências prazerosas com a leitura.

\section{0 prazer de ler e outras tessituras ao caminhar...}

Atuando como professora alfabetizadora, tenho apostado, a cada ano, no aperfeiçoamento das práticas pedagógicas, nos desafios da alfabetização e do letramento e na formação do leitor.

Mas... alfabetizar formando leitores? Como isso ocorre efetivamente?

Marina Colasanti, em outro texto do mesmo livro afirma que formação quer dizer "dar forma". A escritora continua sua explanação dizendo que:

Dá-se forma a algo que existe embora ainda sem feitio, a uma matéria informe, a um esboço de sentimento, a um devenir. Lida assim - há sempre, para tudo, mais de uma leitura possível -, a palavra formação dá outro sentido à frase. E podemos entender que formar leitores não é sacar leitores de dentro da manga, não é fabricar leitores a partir do nada, mas dar forma e sentido a um leitor que já existe, embrionário, dentro de cada um. (COLASANTI, 2005, p. 209).

Estamos formando leitores quando permitimos e estimulamos, no espaço da escola e da sala de aula, o contato com os livros e com as diversas 
possibilidades de leitura. Quando, por exemplo, podemos organizar com nossos alunos uma mini-biblioteca em sala de aula estamos construindo esse processo, haja vista que, ao fazermos isso, potencializamos o leitor que existe dentro de cada ser.

Para isso, vale a pena ousar. Os momentos de leitura devem ser extremamente valorizados. Dessa forma, a prática alfabetizadora pode - e deve - valorizar as rodas de leitura, que se constituem como riquíssimos espaços de troca de experiências, vivências, saberes e suas tessituras. Rodas de notícias, literárias; rodas de ciência, enfim... espaços de contos e (re)contos, leituras, investigações, descobertas.

As rodas de notícias possibilitam um amplo debate sobre as notícias do cotidiano local, regional, nacional e mundial. Após a leitura da notícia levada para a sala de aula pelos meninos e pelas meninas, as professoras podem estimular o debate e a reflexão acerca das informações apresentadas e atividades se desdobram a partir daí. A leitura de gráficos, tabelas e percentuais, símbolos também pode ser bastante explorada e, assim, permitir o confronto de uma "nova" informação com um conhecimento ou com conceitos que já vêm sendo elaborados. As rodas literárias são potenciais impulsionadores e motivadores do contato com o mundo mágico da literatura infanto-juvenil, possibilitando que os estudantes ampliem os seus conhecimentos sobre a literatura, além de proporcionar a troca de impressões e opiniões sobre as histórias lidas ou contadas. As rodas de ciência, por sua vez, podem se empenhar a promover o (re)conhecimento das descobertas científicas e transformar toda essa gama de informações que, muitas vezes, chegam à sala de aula por meio do texto jornalístico, em saberes escolares com aprendizagem significativa.

Valorizar o momento da leitura; compartilhar leituras com os alunos alfabetizandos; explorar a reescrita do que foi lido são algumas possibilidades na realização de uma prática alfabetizadora que se ocupe de e se preocupe com a formação do leitor crítico, que interage com o que lê. 
Além disso, contar e incentivá-los a recontar histórias são atividades enriquecedoras, que potencializam a disputa do prazer de ler, por mais embrionário que ele seja.

Esses são apenas alguns exemplos de como a leitura, como fonte de construção de saberes e de aprendizagem, pode se manter presente no cotidiano das salas de aula de turmas de alfabetização. Além desses materiais, pode-se ler tudo o mais que se encontrar: encarte de supermercado, folhetos, receitas, imagens... A partir do gosto pela leitura que assim vai sendo tecido e do (re)encontro com o prazer de ler, é possível despertar nas crianças, jovens e adultos, o prazer de ler, de ser e tornar-se escritor, como também a tessitura do conhecimento em redes (FERRAÇO, 1999) e ampliação de diferentes saberes, considerando-se suas complexidades e pluralidades. A partir da prática e do despertar do gosto pela leitura e, portanto, do estímulo à formação do leitor, é possível, enfim, caminharmos para a ampliação de como o leitor se percebe e interage com as diferentes possibilidades de leituras existentes na sociedade contemporânea.

Por todos esses motivos, motivações e exemplos apresentados, afirmamos que o trabalho de construção da leitura e da escrita não é tecido individual ou isoladamente. Da formulação de suas hipóteses até a apropriação do sentido dessa leitura pelo leitor e sua compreensão, essa tessitura pressupõe a pesquisa investigativa do que é significativo para o grupo (ou seja, do que, efetivamente, pode se constituir como aprendizagem), a reflexão sobre o que se lê e sobre o que se pretende escrever, constituindo-se como etapas (ou caminhos possíveis) para a produção textual do grupo, seja em grupo ou individualmente.

Ao contrário do que se possa pensar, não há uma receita para que a prática de leitura se torne realidade. É preciso, apenas, que a professora alfabetizadora se vista de uma imensa sensibilidade e perca o medo de ousar, lendo para si e para os seus alunos e fazendo do contato com a leitura 
uma prática cotidiana. Certamente, não devemos perder de vista que para o ato de ler ser mais gostoso e prazeroso, é vital que respeitemos as preferências e o momento de cada sujeito que queremos e desejamos não só alfabetizar, mas que queremos que leia e se aproprie do que lê a partir da compreensão que faz do texto. Como vimos, é fundamental respeitar as preferências e os interesses de leitura do cidadão que desejamos formar leitor.

Respeitando e investindo nessas especificidades, nessas preferências individuais e, também, coletivas, tive, em certa ocasião, numa atividade de avaliação do ano letivo de uma Classe de Alfabetização, o imenso prazer de escutar de uma aluna de sete anos que aprendeu a ler e a escrever. A menina dizia no início do ano letivo que não sabia ler, mas com a minha insistência em dizer-lhe que sabia e que precisava apenas tentar, conseguiu. E eu lhe disse que conseguiu porque perdeu o medo de errar e se permitiu viver a experiência de aprender a ler e a escrever... lendo e escrevendo.

\section{Referências bibliográficas}

COLASANTI, Marina (2004). Fragatas para terras distantes. Rio de Janeiro: Record.

COLASANTI, Marina (2005). Em busca do mapa da mina, ou pensando em formação de leitores. III FÓRUM DE EDUCAÇÃO, Ilha Solteira, São Paulo, 2003. p. 209-219.

FERRAÇO, Carlos Eduardo (1999). Currículos e conhecimentos em redes: as artes de dizer e escrever sobre a arte de fazer. In: ALVES, Nilda; GARCIA, Regina Leite (Orgs.). O sentido da escola. Rio de Janeiro: DP\&A, p. 121-150.

KLEIMAN, Angela. (2004). Modelos de letramento e as práticas de alfabetização na escola. In: KLEIMAN, Angela (Org.). Os significados do letramento: uma nova perspectiva sobre a prática social da escrita. Campinas, SP: Mercado das Letras, p. 15-61.

SOARES, Magda (2003). Letramento: um tema em três gêneros. Belo Horizonte: 
TFOUNI, Leda Verdiani (1997). Letramento e alfabetização. São Paulo: Cortez.

\section{Autora}

\section{Andrea da Paixão Fernandes}

Universidade do Estado do Rio de Janeiro - Instituto de Aplicação Fernando Rodrigues da Silveira (CAp-Uerj).

andreaf@uerj.br

\section{Como citar este artigo:}

FERNANDES, Andrea da Paixão. Alfabetizando e letrando... o despertar e a tessitura de conhecimentos nos caminhos trilhados. Revista ACOALFAplp: Acolhendo a Alfabetização nos Países de Língua portuguesa, São Paulo, ano 2, n. 3, 2007. Disponível em: <http://www.mocambras.org> e ou <http://www.acoalfaplp.org>. Publicado em: setembro 2007. 